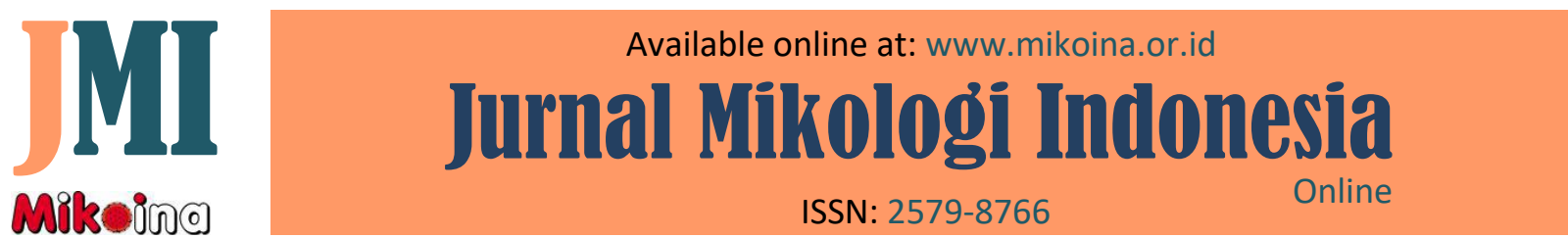

\title{
Analisis Kekerabatan Jamur Ordo Agaricales Berdasarkan Karakter Morfologi di Kawasan Kamojang (Berdasarkan Data Sekunder)
}

\section{Phenetic Relationship of Agaricales Based on Morphological Characteristics in Kamojang (Based on Secondary Data)}

\author{
Nazhira Azzahra', Betty Mayawatie Marzuki ${ }^{1}$, Suryana $^{1}$
}

${ }^{1}$ Departemen Biologi, Fakultas Matematika dan Ilmu Pengetahuan Alam, Universitas Padjadjaran, Jl. Raya Bandung-Sumedang KM. 21, Hegarmanah, Jatinangor, Kabupaten Sumedang, Jawa Barat 45363

Azzahra N, Marzuki BM, Suryana. 2020 - Analisis Kekerabatan Jamur Ordo Agaricales Berdasarkan Karakter Morfologi di Kawasan Kamojang (Berdasarkan Data Sekunder). Jurnal Mikologi Indonesia 4(2), 201-210. doi:10.46638/jmi.v4i2.89

\begin{abstract}
Abstrak
Lima belas spesies jamur Agaricales di Cagar Alam dan Taman Wisata Alam Kamojang, Jawa Barat, koleksi Arko et al. (2017), memiliki beragam karakter morfologi. Jamur tersebut telah dianalisis hubungan kekerabatannya dengan taksonomi numerik. Metode yang digunakan dalam penelitian ini yaitu studi literatur dengan menganalisis data sekundernya menggunakan program SPSS 26.0. Hasil analisis menunjukkan adanya hubungan kekerabatan terdiri dari lima kelompok. Hubungan kekerabatan terdekat yaitu Marasmius sp. 1 dan Marasmius sp. 2 dengan nilai kemiripan sebesar 97,8\%. Hubungan kekerabatan terjauh yaitu Armillaria sp. dan Schizophyllum commune dengan nilai kemiripan sebesar 39\%. Karakter morfologi penentu hubungan kekerabatan ialah karakteristik lamela, tangkai, dan volva.
\end{abstract}

Kata kunci - Agaricales - hubungan kekerabatan - Kamojang - karakter morfologi

\section{Abstract}

Fifteen species of Agaricales mushrooms in Kamojang Nature Reserve and Nature Park, West Java, collected by Arko et al. (2017) have various morphological characteristics. They were analyzed its phenetic relationship by numerical taxonomy using SPSS 26.0. The results showed that the phenetic relationship was divided into five clusters. The closest phenetic relationship is Marasmius sp. 1 and Marasmius sp. 2 with a similarity value of $97.8 \%$. The most distant phenetic relationship is Armillaria sp. and Schizophyllum commune with a similarity value of $39 \%$. Morphological characters that determined this phenetic relationship is its lamellae, stipe, and volva.

Keywords - Agaricales - Kamojang - morphological characteristics - phenetic relationship

\section{Pendahuluan}

Jamur yang termasuk ordo Agaricales memiliki struktur tubuh buah terdiri dari tudung (pileus) dengan bilah (gills/lamella) dan tangkai (stipe/stalk), terdapat pula cincin (annulus) dan volva, namun beberapa spesies jamur hanya memiliki salah satu cincin/volva 
atau tidak keduanya (Kendrick, 2000). Setiap spesies jamur ordo Agaricales memiliki karakter morfologi berbeda. Beberapa spesies jamur memiliki tudung berbilah seperti Lentinula edodes dan Pleurotus ostreatus (Ekowati dkk., 2011), tudung berbentuk seperti koral (Clavaria sp.), tudung berbentuk seperti sarang burung (Cyathus sp.), tudung berpori (Favolaschia sp. dan Fistulina sp.) serta tudung berbentuk seperti bola (Lycoperdon sp.) (Hibbett et al., 2014).

Beragamnya karakter morfologi tubuh buah jamur ordo Agaricales dapat dianalisis hubungan kekerabatannya dengan taksonomi numerik. Taksonomi numerik merupakan metode evaluasi kuantitatif berdasarkan kemiripan sifat antar golongan organisme dan penataan golongan tersebut melalui analisis kelompok (cluster analysis). Taksonomi numerikpun dapat mempermudah dalam menemukan ciri-ciri yang paling dominan untuk pembuatan kunci identifikasi (Tjitrosoepomo, 2017).

Penelitian mengenai keragaman jamur ordo Agaricales yang dilengkapi data karakter morfologinya telah dilakukan oleh Arko et al. (2017). Berdasarkan penelitian tersebut, terdapat 35 spesies jamur makroskopis yang didominasi oleh spesies jamur ordo Agaricales berjumlah 15 spesies. Lima belas spesies jamur ordo Agaricales tersebut memiliki beragam karakter morfologi yang terdiri dari 14 spesies dengan tudung buah berbilah dan satu spesies Fistulina hepatica dengan tudung berpori. Spesies-spesies jamur ordo Agaricales dengan beragam karakter morfologinya dari hasil penelitian Arko et al. (2017) belum dianalisis hubungan kekerabatannya sehingga menarik untuk diteliti. Penelitian ini bertujuan untuk menganalisis hubungan kekerabatan jamur ordo Agaricales dan karakter morfologi yang paling dominan dalam menentukan hubungan kekerabatan tersebut berdasarkan data sekunder penelitian Arko et al. (2017).

\section{Metode Penelitian}

Metode yang digunakan adalah studi literatur dengan menganalisis data-data pada sumber data yang digunakan (Cooper \& Hedges, 2009). Sumber data utama spesies dan karakter morfologi jamur ordo Agaricales di Cagar Alam dan Taman Wisata Alam Kamojang diambil dari penelitian Arko et al. (2017) berjudul The Inventory of Edible Mushrooms in Kamojang Nature Reserve and Nature Park, West Java, Indonesia.

\section{Analisis Kekerabatan Jamur Ordo Agaricales}

Analisis kekerabatan jamur ordo Agaricales menggunakan program SPSS 26.0 (Fatimah, 2013); penentuan Operasional Taksonomi Unit (OTU) yaitu jamur ordo Agaricales. Setiap OTU dianalisis 35 karakter morfologi berdasarkan penelitian Arko dkk. (2017). Setiap karakter morfologi ditentukan skoring 1,2,3 dan seterusnya, karakter yang tidak terdapat pada OTU ditentukan skoring 0 (nol). Pengukuran kemiripan antara OTU menggunakan metode pearson correlation dan pengelompokkan dengan metode between group linkage. Hasil ditampilkan dalam bentuk dendogram.

\section{Analisis Deskripsi Kekerabatan Jamur Ordo Agaricales}

Hubungan kekerabatan jamur ordo Agaricales yang telah dianalisis program SPSS 26.0, kemudian dianalisis secara deskriptif. Data deskriptif mengenai spesies-spesies jamur yang memiliki hubungan kekerabatan terdekat dan terjauh dilengkapi karakter morfologi yang paling dominan dalam penentuan kekerabatannya (Ekowati dkk., 2011; Kusrinah \& Kasiamdari, 2015).

\section{Hasil}

Berdasarkan penelitian Arko et al. 2017 terdapat 15 spesies jamur ordo Agaricales dengan berbagai karakter morfologi di Cagar Alam dan Taman Wisata Alam Kamojang. Dari 
hasil identifikasi terdapat perbaikan nama spesies untuk penelitian tersebut yaitu Marasmiellus sp. 3 menjadi Marasmiellus delicius dan Marasmiellus sp. 4 menjadi Marasmiellus pernambucensis. Setiap spesies jamur ordo Agaricales dan karakter morfologinya dapat dilihat pada Tabel 1.

Setiap spesies jamur ordo Agaricales diberi kode nama ketika dianalisis program SPSS 26.0, yaitu sebagai berikut; Armilaria sp. (AR), Fistulina hepatica (FH), Inocybe sp. (IN), Marasmiellus delicius (MD), Marasmiellus pernambucensis (MP), Marasmiellus sp. 1 (MRS 1), Marasmiellus sp. 2 (MRS 2), Marasmius sp. 1 (MS 1), Marasmius sp. 2 (MS 2), Marasmius sp. 3 (MS 3), Marasmius sp. 4 (MS 4), Oudemansiella sp. (OD), Pleurotus sp. (PS), Pluteus thomsonii (PT), dan Schizophyllum commune (SC). Spesies-spesies jamur ordo Agaricales tersebut dikelompokkan dari nilai kemiripan tertinggi (Tabel 2) dan hubungan kekerabatannya ditampilkan dalam bentuk dendogram (Gambar 1).

Tabel 1. Spesies dan karakter morfologi jamur ordo Agaricales di Cagar Alam dan Taman Wisata Alam Kamojang

\begin{tabular}{|c|c|c|c|c|c|c|}
\hline No. & Karakter & Armillaria sp. & $\begin{array}{l}\text { Fistulina } \\
\text { hepatica }\end{array}$ & Inocybe sp. & $\begin{array}{l}\text { Marasmiellus } \\
\text { delicius }\end{array}$ & $\begin{array}{c}\text { Marasmiellus } \\
\text { pernambucensis }\end{array}$ \\
\hline 1. & $\begin{array}{l}\text { Bentuk } \\
\text { tudung }\end{array}$ & $\begin{array}{l}\text { Convex- } \\
\text { broadly } \\
\text { convex }\end{array}$ & Flabelliform & Broadly convex & $\begin{array}{c}\text { Broadly } \\
\text { parabolic }\end{array}$ & $\begin{array}{c}\text { Broadly convex- } \\
\text { campanulate }\end{array}$ \\
\hline 2. & $\begin{array}{l}\text { Tekstur } \\
\text { permukaan } \\
\text { tudung }\end{array}$ & Smooth & Pruinose & Floccose & Smooth & Smooth \\
\hline 3. & Tepi tudung & Striate-rimos & Lobed & Plane & $\begin{array}{c}\text { Not striate } \\
\text { smooth }\end{array}$ & Striate-recurved \\
\hline 4. & $\begin{array}{l}\text { Diameter } \\
\text { tudung }\end{array}$ & $24-71 \mathrm{~mm}$ & $147 \mathrm{~mm}$ & $17 \mathrm{~mm}$ & $9-12 \mathrm{~mm}$ & $13-15 \mathrm{~mm}$ \\
\hline 5. & $\begin{array}{l}\text { Ketebalan } \\
\text { tudung }\end{array}$ & - & $18 \mathrm{~mm}$ & - & - & - \\
\hline 6. & $\begin{array}{l}\text { Tinggi } \\
\text { tudung }\end{array}$ & $54-83 \mathrm{~mm}$ & $23 \mathrm{~mm}$ & $4 \mathrm{~mm}$ & $19-22 \mathrm{~mm}$ & $4 \mathrm{~mm}$ \\
\hline 7. & $\begin{array}{c}\text { Warna } \\
\text { bercak } \\
\text { (bruise) } \\
\text { tudung }\end{array}$ & $\begin{array}{c}\text { Coklat- } \\
\text { kekuningan }\end{array}$ & $\begin{array}{l}\text { Merah tua } \\
\text { keunguan }\end{array}$ & $\begin{array}{l}\text { Abu tua-abu } \\
\text { muda }\end{array}$ & $\begin{array}{l}\text { Putih-pink } \\
\text { tua }\end{array}$ & Putih \\
\hline 8. & $\begin{array}{c}\text { Warna } \\
\text { daging (flesh) } \\
\text { tudung }\end{array}$ & - & Merah tua & - & - & - \\
\hline 9. & $\begin{array}{c}\text { Warna } \\
\text { permukaan } \\
\text { tudung }\end{array}$ & $\begin{array}{c}\text { Coklat- } \\
\text { kekuningan }\end{array}$ & $\begin{array}{l}\text { Merah tua } \\
\text { keunguan }\end{array}$ & $\begin{array}{l}\text { Abu tua-abu } \\
\text { muda }\end{array}$ & Putih-pink & Putih \\
\hline 10. & $\begin{array}{c}\text { Kedalaman } \\
\text { (depth) } \\
\text { lamela }\end{array}$ & $7 \mathrm{~mm}$ & - & $3 \mathrm{~mm}$ & $3 \mathrm{~mm}$ & $2 \mathrm{~mm}$ \\
\hline 11. & $\begin{array}{c}\text { Jumlah } \\
\text { lamellulae }\end{array}$ & 3 & - & 1 & 2 & 2 \\
\hline 12. & $\begin{array}{l}\text { Perlekatan } \\
\text { lamela pada } \\
\text { tangkai }\end{array}$ & Adnate & - & $\begin{array}{l}\text { Free (tidak } \\
\text { melekat) }\end{array}$ & Adnate & Deccurent \\
\hline 13. & $\begin{array}{c}\text { Tepi } \\
\text { (margin) } \\
\text { lamela }\end{array}$ & Even & - & Even & Even & Even \\
\hline
\end{tabular}


Azzahra dkk., 2020

\begin{tabular}{|c|c|c|c|c|c|c|}
\hline No. & Karakter & Armillaria sp. & $\begin{array}{l}\text { Fistulina } \\
\text { hepatica }\end{array}$ & Inocybe sp. & $\begin{array}{c}\text { Marasmiellus } \\
\text { delicius }\end{array}$ & $\begin{array}{c}\text { Marasmiellus } \\
\text { pernambucensis }\end{array}$ \\
\hline 14. & Tipe lamela & Regular & - & Regular & Regular & Regular \\
\hline 15. & $\begin{array}{c}\text { Tipe } \\
\text { pewarnaan } \\
\text { lamela }\end{array}$ & Discolorous & - & Concolorous & Concolorous & Concolorous \\
\hline 16. & $\begin{array}{l}\text { Warna } \\
\text { lamela }\end{array}$ & Putih-krem & - & Pink muda & Putih & Putih \\
\hline 17. & $\begin{array}{l}\text { Bentuk } \\
\text { tangkai }\end{array}$ & Equal & Tapered at apex & Tapered at base & Equal & Equal \\
\hline 18. & $\begin{array}{c}\text { Diameter } \\
\text { basis tangkai }\end{array}$ & $5-9 \mathrm{~mm}$ & $20 \mathrm{~mm}$ & $4 \mathrm{~mm}$ & $3 \mathrm{~mm}$ & $3 \mathrm{~mm}$ \\
\hline 19. & $\begin{array}{c}\text { Diameter } \\
\text { tengah } \\
\text { tangkai }\end{array}$ & $5-9 \mathrm{~mm}$ & $24 \mathrm{~mm}$ & $3 \mathrm{~mm}$ & $3 \mathrm{~mm}$ & $3 \mathrm{~mm}$ \\
\hline 20. & $\begin{array}{c}\text { Diameter } \\
\text { ujung tangkai }\end{array}$ & $5-9 \mathrm{~mm}$ & $27 \mathrm{~mm}$ & $3 \mathrm{~mm}$ & $3 \mathrm{~mm}$ & $3 \mathrm{~mm}$ \\
\hline 21. & $\begin{array}{l}\text { Panjang } \\
\text { tangkai }\end{array}$ & 83-108 mm & $38 \mathrm{~mm}$ & $29 \mathrm{~mm}$ & $14-21 \mathrm{~mm}$ & $20-23 \mathrm{~mm}$ \\
\hline 22. & $\begin{array}{l}\text { Permukaan } \\
\text { tangkai }\end{array}$ & $\begin{array}{l}\text { Squamulose- } \\
\text { fibrilose }\end{array}$ & Smooth & $\begin{array}{l}\text { Fibrilose- } \\
\text { strigose }\end{array}$ & Smooth & Smooth \\
\hline 23. & $\begin{array}{l}\text { Perlekatan } \\
\text { tangkai pada } \\
\text { substrat }\end{array}$ & Caepitose & Inserted & Inserted & Inserted & Inserted \\
\hline 24. & $\begin{array}{l}\text { Perlekatan } \\
\text { tangkai pada } \\
\text { tudung }\end{array}$ & Central & Lateral & Central & Central & Central \\
\hline 25. & $\begin{array}{l}\text { Tipe daging } \\
\text { (flesh) } \\
\text { tangkai }\end{array}$ & Stuffed & Solid & Solid & Solid & Solid \\
\hline 26. & $\begin{array}{c}\text { Warna } \\
\text { bercak } \\
\text { (bruise) } \\
\text { tangkai }\end{array}$ & $\begin{array}{c}\text { Krem } \\
\text { kemerahan }\end{array}$ & $\begin{array}{c}\text { Merah } \\
\text { keunguan }\end{array}$ & Abu muda & Pink & Putih \\
\hline 27. & $\begin{array}{c}\text { Warna } \\
\text { daging (flesh) } \\
\text { tangkai }\end{array}$ & $\begin{array}{l}\text { Krem muda } \\
\text { kemerahan }\end{array}$ & Merah tua & Abu muda & Putih & Putih \\
\hline 28. & $\begin{array}{c}\text { Warna } \\
\text { permukaan } \\
\text { tangkai }\end{array}$ & $\begin{array}{l}\text { Krem muda } \\
\text { kemerahan }\end{array}$ & $\begin{array}{c}\text { Merah } \\
\text { keunguan }\end{array}$ & Abu muda & Pink & Putih \\
\hline 29. & Annulus & $\begin{array}{l}\text { Superior- } \\
\text { single }\end{array}$ & - & - & - & - \\
\hline 30. & Volva & - & - & - & - & - \\
\hline 31. & Jejak spora & - & - & - & - & - \\
\hline 32. & Tes $\mathrm{KOH}$ & Negatif & Negatif & Negatif & Negatif & Negatif \\
\hline 33. & Bentuk pori & - & Round & - & - & - \\
\hline 34. & Ukuran pori & - & $5 \mathrm{~mm}$ & - & - & - \\
\hline 35. & Warna pori & - & Pink & - & - & - \\
\hline
\end{tabular}




\begin{tabular}{|c|c|c|c|c|c|c|}
\hline No. & Karakter & $\begin{array}{c}\text { Marasmiellus } \\
\text { sp. } 1\end{array}$ & $\begin{array}{l}\text { Marasmiellus } \\
\text { sp. } 2\end{array}$ & $\begin{array}{c}\text { Marasmius } \\
\text { sp. } 1\end{array}$ & $\begin{array}{l}\text { Marasmius } \\
\text { sp. } 2\end{array}$ & $\begin{array}{c}\text { Marasmius } \\
\text { sp. } 3\end{array}$ \\
\hline 1. & $\begin{array}{l}\text { Bentuk } \\
\text { tudung }\end{array}$ & $\begin{array}{c}\text { Slightly } \\
\text { depressed }\end{array}$ & $\begin{array}{l}\text { Moderate- } \\
\text { indented }\end{array}$ & $\begin{array}{c}\text { Broadly } \\
\text { convex-plane }\end{array}$ & Convex & $\begin{array}{c}\text { Broadly } \\
\text { parabolic }\end{array}$ \\
\hline 2. & $\begin{array}{l}\text { Tekstur } \\
\text { permukaan } \\
\text { tudung }\end{array}$ & Smooth & Smooth & Smooth & Smooth & Smooth \\
\hline 3. & Tepi tudung & $\begin{array}{l}\text { Not striate } \\
\text { smooth }\end{array}$ & Sulcate-striate & $\begin{array}{l}\text { Incurved- } \\
\text { decurved }\end{array}$ & $\begin{array}{l}\text { Not striate } \\
\text { smooth }\end{array}$ & $\begin{array}{c}\text { Not striate } \\
\text { smooth }\end{array}$ \\
\hline 4. & $\begin{array}{l}\text { Diameter } \\
\text { tudung }\end{array}$ & $52 \mathrm{~mm}$ & $65 \mathrm{~mm}$ & $4-8 \mathrm{~mm}$ & $6 \mathrm{~mm}$ & 5-7 mm \\
\hline 5. & $\begin{array}{l}\text { Ketebalan } \\
\text { tudung }\end{array}$ & - & - & - & - & - \\
\hline 6. & $\begin{array}{l}\text { Tinggi } \\
\text { tudung }\end{array}$ & $4 \mathrm{~mm}$ & $9 \mathrm{~mm}$ & $2 \mathrm{~mm}$ & $4 \mathrm{~mm}$ & $16-19 \mathrm{~mm}$ \\
\hline 7. & $\begin{array}{l}\text { Warna } \\
\text { bercak } \\
\text { (bruise) } \\
\text { tudung }\end{array}$ & Putih & Putih-abu muda & Putih & Putih & Putih-pink \\
\hline 8. & $\begin{array}{c}\text { Warna } \\
\text { daging (flesh) } \\
\text { tudung }\end{array}$ & - & - & - & - & - \\
\hline 9. & $\begin{array}{l}\text { Warna } \\
\text { permukaan } \\
\text { tudung }\end{array}$ & Putih & Putih-abu muda & Putih & Putih & Putih-pink \\
\hline 10. & $\begin{array}{c}\text { Kedalaman } \\
\text { (depth) } \\
\text { lamela }\end{array}$ & $3 \mathrm{~mm}$ & $4 \mathrm{~mm}$ & $1 \mathrm{~mm}$ & $1 \mathrm{~mm}$ & $1 \mathrm{~mm}$ \\
\hline 11. & $\begin{array}{c}\text { Jumlah } \\
\text { lamellulae }\end{array}$ & 3 & 3 & 0 & 0 & 0 \\
\hline 12. & $\begin{array}{l}\text { Perlekatan } \\
\text { lamela pada } \\
\text { tangkai }\end{array}$ & Adnexed & $\begin{array}{c}\text { Free (tidak } \\
\text { melekat) }\end{array}$ & $\begin{array}{c}\text { Free (tidak } \\
\text { melekat) }\end{array}$ & $\begin{array}{c}\text { Free (tidak } \\
\text { melekat) }\end{array}$ & Deccurent \\
\hline 13. & $\begin{array}{c}\text { Tepi } \\
\text { (margin) } \\
\text { lamela }\end{array}$ & Serrate & Serrate & Even & Even & Even \\
\hline 14. & Tipe lamela & Regular & Regular & Regular & Regular & Regular \\
\hline 15. & $\begin{array}{c}\text { Tipe } \\
\text { pewarnaan } \\
\text { lamela }\end{array}$ & Concolorous & Concolorous & Concolorous & Concolorous & Concolorous \\
\hline 16. & $\begin{array}{l}\text { Warna } \\
\text { lamela }\end{array}$ & Pink muda & Putih & Putih & Putih & Putih \\
\hline 17. & $\begin{array}{l}\text { Bentuk } \\
\text { tangkai }\end{array}$ & $\begin{array}{l}\text { Tapered at } \\
\text { base }\end{array}$ & Equal & Equal & Equal & Equal \\
\hline 18. & $\begin{array}{c}\text { Diameter } \\
\text { basis tangkai }\end{array}$ & $4 \mathrm{~mm}$ & $7 \mathrm{~mm}$ & $1 \mathrm{~mm}$ & $1 \mathrm{~mm}$ & $2 \mathrm{~mm}$ \\
\hline 19. & $\begin{array}{c}\text { Diameter } \\
\text { tengah } \\
\text { tangkai }\end{array}$ & $4 \mathrm{~mm}$ & $7 \mathrm{~mm}$ & $1 \mathrm{~mm}$ & $1 \mathrm{~mm}$ & $2 \mathrm{~mm}$ \\
\hline 20 & $\begin{array}{c}\text { Diameter } \\
\text { ujung tangkai }\end{array}$ & $4 \mathrm{~mm}$ & $7 \mathrm{~mm}$ & $1 \mathrm{~mm}$ & $1 \mathrm{~mm}$ & $2 \mathrm{~mm}$ \\
\hline 21. & $\begin{array}{l}\text { Panjang } \\
\text { tangkai }\end{array}$ & $51 \mathrm{~mm}$ & $66 \mathrm{~mm}$ & $15-30 \mathrm{~mm}$ & $28 \mathrm{~mm}$ & $14-24 \mathrm{~mm}$ \\
\hline 22. & $\begin{array}{l}\text { Permukaan } \\
\text { tangkai }\end{array}$ & Smooth & Smooth-strigose & Smooth & Smooth & Smooth \\
\hline 23. & $\begin{array}{l}\text { Perlekatan } \\
\text { tangkai pada } \\
\text { substrat }\end{array}$ & Inserted & Mycelial pad & $\begin{array}{l}\text { Attached to } \\
\text { rhizomorph }\end{array}$ & $\begin{array}{l}\text { Attached to } \\
\text { rhizomorph }\end{array}$ & $\begin{array}{l}\text { Attached to } \\
\text { rhizomorph }\end{array}$ \\
\hline
\end{tabular}




\begin{tabular}{|c|c|c|c|c|c|c|}
\hline No. & Karakter & $\begin{array}{c}\text { Marasmiellus } \\
\text { sp. } 1\end{array}$ & $\begin{array}{c}\text { Marasmiellus } \\
\text { sp. } 2\end{array}$ & $\begin{array}{l}\text { Marasmius } \\
\text { sp. } 1\end{array}$ & $\begin{array}{l}\text { Marasmius } \\
\quad \text { sp. } 2\end{array}$ & $\begin{array}{l}\text { Marasmius } \\
\quad \text { sp. } 3\end{array}$ \\
\hline 24. & $\begin{array}{l}\text { Perlekatan } \\
\text { tangkai pada } \\
\text { tudung }\end{array}$ & Central & Central & Central & Central & Central \\
\hline 25. & $\begin{array}{l}\text { Tipe daging } \\
\text { (flesh) } \\
\text { tangkai }\end{array}$ & Solid & Solid & Hollow & Solid & Solid \\
\hline 26. & $\begin{array}{l}\text { Warna } \\
\text { bercak } \\
\text { (bruise) } \\
\text { tangkai }\end{array}$ & Pink muda & Krem tua-pink & Putih & Putih & Putih \\
\hline 27. & $\begin{array}{c}\text { Warna } \\
\text { daging (flesh) } \\
\text { tangkai }\end{array}$ & Putih & Pink muda & Putih & Putih & Putih \\
\hline 28. & $\begin{array}{l}\text { Warna } \\
\text { permukaan } \\
\text { tangkai }\end{array}$ & Pink muda & Krem tua-pink & Putih & Putih & Putih \\
\hline 29. & Annulus & - & - & - & - & - \\
\hline 30. & Volva & - & - & - & - & - \\
\hline 31. & Jejak spora & - & - & - & - & - \\
\hline 32. & Tes KOH & Negatif & Negatif & Negatif & Negatif & Negatif \\
\hline 33. & Bentuk pori & - & - & - & - & - \\
\hline 34. & Ukuran pori & - & - & - & - & - \\
\hline 35. & Warna pori & - & - & - & - & - \\
\hline No. & Karakter & $\begin{array}{l}\text { Marasmius } \\
\quad \text { sp. } 4\end{array}$ & $\begin{array}{c}\text { Oudemansiella } \\
\text { sp. }\end{array}$ & Pleurotus sp. & $\begin{array}{c}\text { Pluteus } \\
\text { thomsonii }\end{array}$ & $\begin{array}{c}\text { Schizophyllum } \\
\text { commune }\end{array}$ \\
\hline 1. & $\begin{array}{l}\text { Bentuk } \\
\text { tudung }\end{array}$ & Convex & $\begin{array}{c}\text { Plane-slightly } \\
\text { depressed }\end{array}$ & Broadly convex & $\begin{array}{l}\text { Convex- } \\
\text { broadly } \\
\text { convex }\end{array}$ & Conchate \\
\hline 2. & $\begin{array}{l}\text { Tekstur } \\
\text { permukaan } \\
\text { tudung }\end{array}$ & Smooth & Smooth & Smooth & Veined & Floccose \\
\hline 3. & Tepi tudung & $\begin{array}{l}\text { Not striate } \\
\text { smooth }\end{array}$ & Decurved & $\begin{array}{l}\text { Incurved- } \\
\text { smooth }\end{array}$ & Plane & Incurved \\
\hline 4. & $\begin{array}{l}\text { Diameter } \\
\text { tudung }\end{array}$ & $7-11 \mathrm{~mm}$ & $120 \mathrm{~mm}$ & $12-23 \mathrm{~mm}$ & $10-21 \mathrm{~mm}$ & $6-40 \mathrm{~mm}$ \\
\hline 5. & $\begin{array}{l}\text { Ketebalan } \\
\text { tudung }\end{array}$ & - & $8 \mathrm{~mm}$ & $1 \mathrm{~mm}$ & $2 \mathrm{~mm}$ & - \\
\hline 6. & $\begin{array}{l}\text { Tinggi } \\
\text { tudung }\end{array}$ & $3 \mathrm{~mm}$ & $90 \mathrm{~mm}$ & $4-6 \mathrm{~mm}$ & $5-7 \mathrm{~mm}$ & $4-7 \mathrm{~mm}$ \\
\hline 7. & $\begin{array}{l}\text { Warna } \\
\text { bercak } \\
\text { (bruise) } \\
\text { tudung }\end{array}$ & Putih-pink & $\begin{array}{l}\text { Krem muda- } \\
\text { krem tua }\end{array}$ & Coklat muda & $\begin{array}{l}\text { Abu tua-abu } \\
\text { muda }\end{array}$ & Putih-abu muda \\
\hline 8. & $\begin{array}{c}\text { Warna } \\
\text { daging (flesh) } \\
\text { tudung }\end{array}$ & - & Pink & Putih & $\mathrm{Abu}$ & - \\
\hline 9. & $\begin{array}{l}\text { Warna } \\
\text { permukaan } \\
\text { tudung }\end{array}$ & Putih-pink & $\begin{array}{l}\text { Krem muda- } \\
\text { krem tua }\end{array}$ & Coklat muda & $\begin{array}{l}\text { Abu tua-abu } \\
\text { muda }\end{array}$ & Putih-abu muda \\
\hline 10. & $\begin{array}{l}\text { Kedalaman } \\
\text { (depth) } \\
\text { lamela }\end{array}$ & $2 \mathrm{~mm}$ & $10 \mathrm{~mm}$ & $1 \mathrm{~mm}$ & $4-6 \mathrm{~mm}$ & $1 \mathrm{~mm}$ \\
\hline 11. & $\begin{array}{c}\text { Jumlah } \\
\text { lamellulae }\end{array}$ & 3 & 3 & 2 & 2 & 2 \\
\hline 12. & $\begin{array}{l}\text { Perlekatan } \\
\text { lamela pada } \\
\text { tangkai }\end{array}$ & $\begin{array}{c}\text { Free (tidak } \\
\text { melekat) }\end{array}$ & Adnexed & Deccurent & $\begin{array}{c}\text { Free (tidak } \\
\text { melekat) }\end{array}$ & $\begin{array}{c}\text { Free (tidak } \\
\text { melekat) }\end{array}$ \\
\hline
\end{tabular}




\begin{tabular}{|c|c|c|c|c|c|c|}
\hline No. & Karakter & $\begin{array}{c}\text { Marasmius } \\
\text { sp. } 4 \\
\end{array}$ & $\begin{array}{c}\text { Oudemansiella } \\
\text { sp. }\end{array}$ & Pleurotus sp. & $\begin{array}{c}\text { Pluteus } \\
\text { thomsonii }\end{array}$ & $\begin{array}{c}\text { Schizophyllum } \\
\text { commune }\end{array}$ \\
\hline 13. & $\begin{array}{c}\text { Tepi } \\
\text { (margin) } \\
\text { lamela }\end{array}$ & Even & Even & Even & Even & Even \\
\hline 14. & Tipe lamela & Regular & Regular & Regular & Regular & Regular \\
\hline 15. & $\begin{array}{c}\text { Tipe } \\
\text { pewarnaan } \\
\text { lamela }\end{array}$ & Concolorous & Concolorous & Concolorous & Concolorous & Concolorous \\
\hline 16. & $\begin{array}{l}\text { Warna } \\
\text { lamela }\end{array}$ & Putih & Putih & Putih & $\mathrm{Abu}$ & Abu muda \\
\hline 17. & $\begin{array}{l}\text { Bentuk } \\
\text { tangkai }\end{array}$ & Equal & Equal & Tapered at base & Equal & - \\
\hline 18. & $\begin{array}{c}\text { Diameter } \\
\text { basis tangkai }\end{array}$ & $2 \mathrm{~mm}$ & $9 \mathrm{~mm}$ & $2 \mathrm{~mm}$ & $2-4 \mathrm{~mm}$ & - \\
\hline 19. & $\begin{array}{c}\text { Diameter } \\
\text { tengah } \\
\text { tangkai }\end{array}$ & $2 \mathrm{~mm}$ & $9 \mathrm{~mm}$ & $3 \mathrm{~mm}$ & $2-4 \mathrm{~mm}$ & - \\
\hline 20 & $\begin{array}{c}\text { Diameter } \\
\text { ujung tangkai }\end{array}$ & $2 \mathrm{~mm}$ & $9 \mathrm{~mm}$ & $5 \mathrm{~mm}$ & $2-4 \mathrm{~mm}$ & - \\
\hline 21. & $\begin{array}{l}\text { Panjang } \\
\text { tangkai }\end{array}$ & $13-20 \mathrm{~mm}$ & $93 \mathrm{~mm}$ & $11 \mathrm{~mm}$ & $31-40 \mathrm{~mm}$ & - \\
\hline 22. & $\begin{array}{l}\text { Permukaan } \\
\text { tangkai }\end{array}$ & Smooth & Smooth & Smooth & $\begin{array}{l}\text { Fibrilose- } \\
\text { pubescent }\end{array}$ & - \\
\hline 23. & $\begin{array}{l}\text { Perlekatan } \\
\text { tangkai pada } \\
\text { substrat }\end{array}$ & $\begin{array}{l}\text { Attached to } \\
\text { rhizomorph }\end{array}$ & Inserted & Inserted & Inserted & Inserted \\
\hline 24. & $\begin{array}{l}\text { Perlekatan } \\
\text { tangkai pada } \\
\text { tudung }\end{array}$ & Central & Central & Lateral & Central & Sesile \\
\hline 25. & $\begin{array}{c}\text { Tipe daging } \\
\text { (flesh) } \\
\text { tangkai }\end{array}$ & Solid & Hollow & Solid & Hollow & - \\
\hline 26. & $\begin{array}{l}\text { Warna } \\
\text { bercak } \\
\text { (bruise) } \\
\text { tangkai }\end{array}$ & Putih & Putih & Putih & Abu muda & - \\
\hline 27. & $\begin{array}{c}\text { Warna } \\
\text { daging (flesh) } \\
\text { tangkai }\end{array}$ & Putih & Putih & Putih & Putih & - \\
\hline 28. & $\begin{array}{l}\text { Warna } \\
\text { permukaan } \\
\text { tangkai }\end{array}$ & Putih & Putih & Putih & Abu muda & - \\
\hline 29. & Annulus & - & - & - & - & - \\
\hline 30. & Volva & - & - & - & - & - \\
\hline 31. & Jejak spora & - & Putih & - & - & - \\
\hline 32. & Tes $\mathrm{KOH}$ & Negatif & Negatif & Negatif & Negatif & Negatif \\
\hline 33. & Bentuk pori & - & - & - & - & - \\
\hline 34. & Ukuran pori & - & - & - & - & - \\
\hline 35. & Warna pori & - & - & - & - & - \\
\hline
\end{tabular}

Tabel 2. Pengelompokkan spesies-spesies jamur ordo Agaricales di Cagar Alam dan Taman Wisata

\begin{tabular}{|c|c|c|c|c|}
\hline Stage & Nama spesies & Nama spesies & Nilai kemiripan & $\begin{array}{l}\text { Next } \\
\text { stage }\end{array}$ \\
\hline 1. & Marasmius sp. 1 & Marasmius sp. 2 & $97,8 \%$ & 4 \\
\hline 2. & Marasmius sp. 3 & Marasmius sp. 4 & $96,6 \%$ & 4 \\
\hline 3. & Marasmiellus sp. 1 & Marasmiellus delicius & $93,2 \%$ & 6 \\
\hline 4. & Marasmius sp. 1 & Marasmius sp. 3 & $92,1 \%$ & 9 \\
\hline 5. & Oudemansiella sp. & Pleurotus sp. & $91,4 \%$ & 10 \\
\hline
\end{tabular}




\begin{tabular}{|c|c|c|c|c|}
\hline Stage & Nama spesies & Nama spesies & Nilai kemiripan & $\begin{array}{l}\text { Next } \\
\text { stage }\end{array}$ \\
\hline 6. & Marasmiellus sp. 1 & Inocybe sp. & $91,3 \%$ & 7 \\
\hline 7. & Marasmiellus pernambucensis & Inocybe sp. & $88,9 \%$ & 8 \\
\hline 8. & Marasmiellus sp. 2 & Inocybe sp. & $87,2 \%$ & 9 \\
\hline 9. & Marasmius sp. 1 & Inocybe sp. & $86 \%$ & 11 \\
\hline 10. & Oudemansiella sp. & Pluteus thomsonii & $83,9 \%$ & 11 \\
\hline 11. & Inocybe sp. & Oudemansiella sp. & $78,6 \%$ & 12 \\
\hline 12. & Armilaria sp. & Inocybe sp. & $55,6 \%$ & 13 \\
\hline 13. & Armilaria sp. & Fistulina hepatica & $49,5 \%$ & 14 \\
\hline 14. & Armilaria sp. & Schizophyllum commune & $39 \%$ & 0 \\
\hline
\end{tabular}

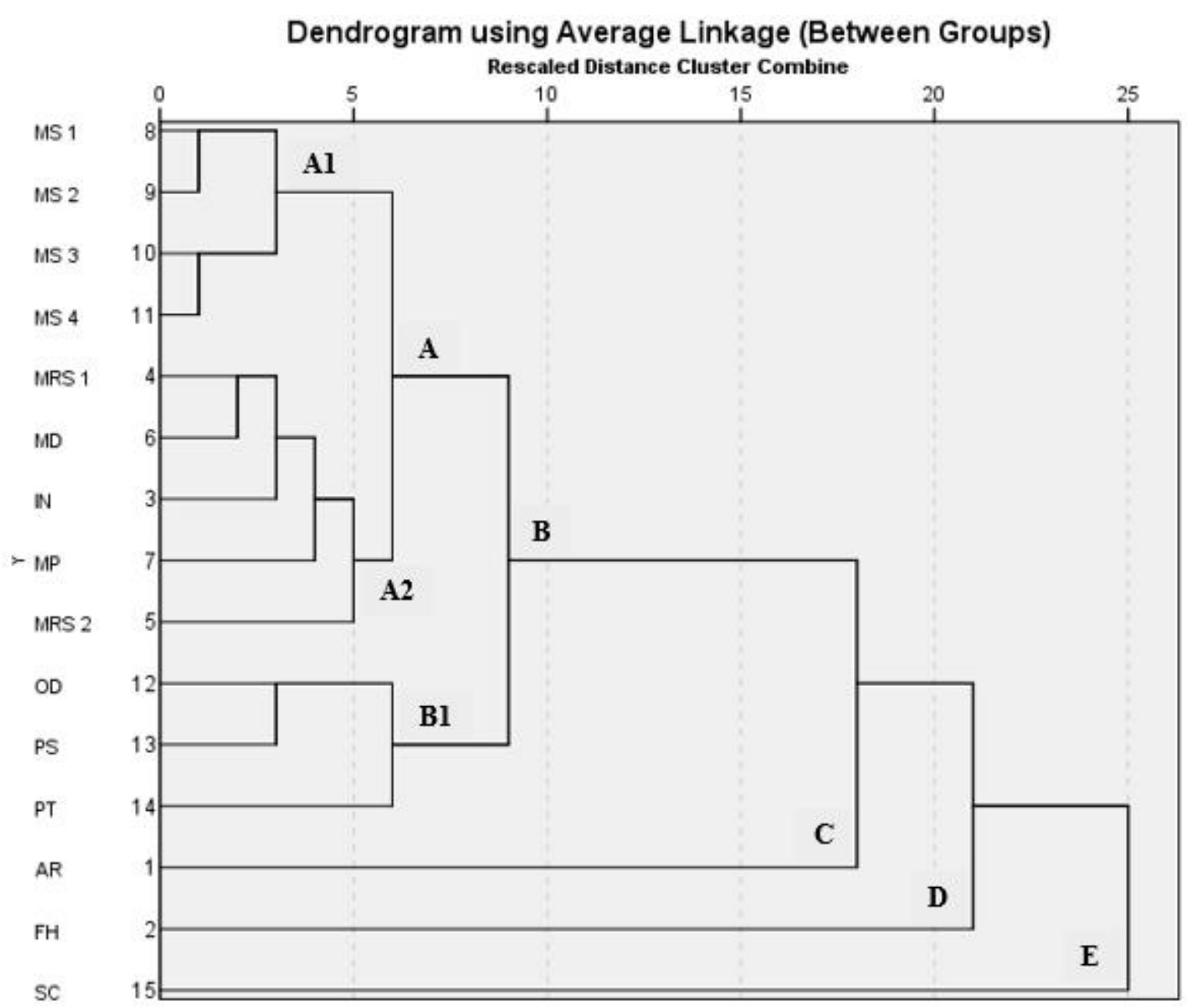

Gambar 1. Hubungan kekerabatan jamur ordo Agaricales di Cagar Alam dan Taman Wisata Alam Kamojang

\section{Pembahasan}

Pada penelitian Arko et al. (2017), terdapat perbaikan nama spesies Marasmiellus sp. 3 menjadi Marasmiellus delicius dan Marasmiellus sp. 4 menjadi Marasmiellus pernambucensis. Perbaikan nama Marasmiellus sp. 3 disebabkan spesies tersebut memiliki karakter yang sama seperti Marasmiellus delicius sesuai hasil penelitian Retnowati (2018) yaitu tepi tudung bertipe non-striate hingga short striate, perlekatan lamela pada tangkai bertipe adnate hingga subdeccurent, lamellulae berjumlah 1-3, warna lamela putih, perlekatan tangkai pada tudung berada di tengah (central), dan bentuk tangkai tipe equal. Sementara perbaikan nama Marasmiellus sp. 4 disebabkan spesies tersebut memiliki karakter 
yang sama seperti Marasmiellus pernambucensis sesuai hasil penelitian Retnowati (2018) yaitu bentuk tudung convex, warna tudung putih, perlekatan lamela pada tangkai bertipe adnate hingga short deccurent, lamellulae berjumlah 1-2, warna lamela putih, bentuk tangkai tipe equal, dan warna tangkai putih.

Pada dendogram, hubungan kekerabatan 15 spesies jamur ordo Agaricales di Cagar Alam dan Taman Wisata Alam Kamojang Jawa Barat membentuk lima kelompok besar yaitu kelompok A, B, C, D, dan E. Kelompok A terdiri dari hubungan kekerabatan spesies-spesies pada sub-kelompok A1 dan A2. Sub-kelompok A1 terdapat hubungan kekerabatan empat spesies Marasmius sebesar 92,1-97,8\% (Tabel 2) dengan 20-26 karakter morfologi yang sama dari 35 karakter yang dianalisis (Tabel 1). Hubungan kekerabatan terdekat terdapat pada sub-kelompok A1 yaitu Marasmius sp. 1 dan Marasmius sp. 2 sebesar 97,8\%. Pada subkelompok A2 terdapat hubungan kekerabatan antar empat spesies Marasmiellus dan Inocybe sp. sebesar 87,2-93,2\% (Tabel 2) dengan 11-16 karakter morfologi yang sama (Tabel 1). Hubungan kekerabatan Marasmius sp. 1 (sub-kelompok A1) dengan Inocybe sp. (subkelompok A2) membentuk kelompok besar yaitu kelompok A sebesar 86\% (Tabel 2) dengan 11 karakter morfologi yang sama (Tabel 1). Hubungan kekerabatan spesies-spesies Inocybe, Marasmiellus dan Marasmius terbentuk karena adanya kesamaan karakter morfologi yaitu tipe lamela (regular), tipe pewarnaan lamela (concolorous), perlekatan tangkai pada tudung (central), tidak adanya cincin, tidak adanya volva, dan tes $\mathrm{KOH}$ (negatif).

Kelompok B terdiri dari hubungan kekerabatan spesies-spesies pada sub-kelompok B1 dan kelompok A. Pada sub-kelompok B1 menunjukkan hubungan kekerabatan Oudemansiella sp. dengan Pleurotus sp. sebesar 91,4\% dan Oudemansiella sp. dengan Pluteus thomsonii sebesar 83,9\% (Tabel 2) dengan 11-14 karakter morfologi yang sama (Tabel 1). Inocybe sp. (kelompok A) berkerabat dengan Oudemansiella sp. (sub-kelompok B1) sebesar 78,6\% (Tabel 2) membentuk kelompok besar yaitu kelompok B karena adanya kesamaan karakter morfologi yaitu tepi lamela (even), tipe lamela (regular), tipe pewarnaan lamela (concolorous), perlekatan tangkai pada tudung (central), perlekatan tangkai pada substrat (inserted), tidak adanya cincin, tidak adanya volva, dan tes $\mathrm{KOH}$ (negatif).

Hubungan kekerabatan spesies-spesies jamur ordo Agaricales pada kelompok A dan B memiliki nilai kemiripan berkisar 78,6-97,8\% (Tabel 2). Hubungan kekerabatan tersebut terbentuk karena antar spesies-spesiesnya memiliki kesamaan karakter morfologi berjumlah 11-26 karakter morfologi dari 35 karakter morfologi yang dianalisis (Tabel 1). Hubungan kekerabatan dengan tingkat kemiripan yang tinggi disebabkan memiliki banyak kesamaan karakter morfologi (Ekowati dkk., 2011).

Kelompok B memisah dengan kelompok $\mathrm{C}$ dengan adanya hubungan kekerabatan Armillaria sp. dan Inocybe sp. sebesar 55,6\% (Tabel 2) karena hanya terdapat tujuh karakter morfologi yang sama yaitu bentuk tudung (broadly convex), tepi lamela (even), tipe lamela (regular), perlekatan tangkai pada tudung (central), tidak adanya volva, jejak spora (tidak ada warna), dan tes $\mathrm{KOH}$.

Kelompok C memisah dengan kelompok D karena adanya hubungan kekerabatan Armillaria sp. dengan Fistulina hepatica sebesar 49,5\% (Tabel 2) disebabkan sedikitnya persamaan karakter yaitu tidak adanya volva, warna jejak spora (tidak ada warna), dan tes $\mathrm{KOH}$ (negatif). Perbedaan yang jelas terlihat diantara dua spesies ini yaitu Armilaria sp. memiliki lamela, sementara Fistulina hepatica memiliki pori pada bagian bawah tudungnya. Fistulina hepatica termasuk ordo Agaricales bukan berdasarkan kesamaan karakter morfologi, tetapi karena kesamaan molekular. Kesamaan molekular tersebut menunjukkan Fistulina hepatica berkerabat dekat dengan Schizophyllum commune (Hubregtse, 2019).

Kelompok D memisah dengan kelompok E karena adanya hubungan kekerabatan terjauh sebesar 39\% antara Armilaria sp. dengan Schizophyllum commune (Tabel 2). Terbentuknya hubungan kekerabatan terjauh tersebut karena hanya terdapat sedikit 
persamaan karakter seperti tepi lamela (even), tipe lamela (regular), tidak adanya volva, jejak spora (tidak ada warna), dan tes $\mathrm{KOH}$ (negatif).

Hubungan kekerabatan spesies-spesies jamur ordo Agaricales yang memisah pada kelompok C, kelompok D, dan kelompok E memiliki nilai kemiripan sebesar 39-55,6\% (Tabel 2). Hubungan kekerabatan tersebut terbentuk karena antar spesies-spesiesnya hanya memiliki kesamaan karakter morfologi berjumlah 3-7 karakter morfologi dari 35 karakter morfologi yang dianalisis (Tabel 1). Berdasarkan data pada penelitian Kusrinah \& Kasiamdari (2015), hubungan kekerabatan dengan nilai kemiripan yang rendah disebabkan hanya terdapat sedikit kesamaan karakter morfologi.

Berdasarkan hasil analisis deskriptif, karakter morfologi yang paling dominan dalam penentuan hubungan kekerabatan jamur ordo Agaricales di Cagar Alam dan Taman Wisata Alam Kamojang ialah tepi lamela (even), tipe lamela (regular), tipe pewarnaan lamela (concolorous), tipe perlekatan tangkai pada tudung (central), dan tidak adanya volva. Menurut Krug et al. (2004), karakteristik lamela seperti tepi atau perlekatannya dapat digunakan untuk penentuan genus jamur. Perlekatan tangkai pada bagian tengah (central) tudung merupakan karakter jamur ordo Agaricales (Tjitrosoepomo, 2011) dan volva merupakan karakter morfologi jamur ordo Agaricales yang hanya dimiliki spesies Amanita, Volvariella dan Volvopluteus (Kuo, 2019).

Hubungan kekerabatan lima belas spesies jamur ordo Agaricales di Cagar Alam dan Taman Wisata Alam Kamojang, Jawa Barat terbagi ke dalam lima kelompok dengan nilai kemiripan berkisar dari 39-97,8\%. Hubungan kekerabatan tersebut ditentukan oleh karakter morfologi lamela, tangkai, dan volva.

\section{Pustaka}

Arko, P. F., Marzuki, B. M. \& Kusmoro, J. (2017). The inventory of edible mushroom in Kamojang Nature Reserve and Nature Park, West Java, Indonesia. Biodiversitas, 18(2), 530-540. https://doi.org/10.13057/biodiv/d180213

Cooper, H. \& Hedges, L. V. (2009). Research synthesis as a scientific process. In H. Cooper, L.V. Hedges. \& J.C. Valentine (Eds.). The Handbook of Research Synthesis and Metaanalysis ( $2^{\text {nd }}$ edition, pp. 3-16). Russel Sage Foundation.

Ekowati, N., Kasiamdari, R. S., Pusposendjojo, N. \& Soegihardjo, C. J. (2011). Hubungan kekerabatan fenetik jamur shiitake (Lentinula edodes (Berk.) Pegler) berdasarkan karakter morfologi. Biosfera, 29(1), 110-117.

Fatimah, S. (2013). Analisis morfologi dan hubungan kekerabatan sebelas jenis tanaman salak (Salacca zalacca (Gertner) Voss) Bangkalan. Agrovigor, 6(1), 1-15.

Hibbett, D. S., Bauer, R., Binder, M., Giachini, A. J., Hosaka, K., Justo, A., Larrson, E., Larrson, K. H., Lawrey, J. D., Miettinen, O., Nagy, L. G., Nillson, R. H., Weiss, M. \& Thorn, R. G. (2014). Agaricomycetes. In D.J. McLaughlin. \& J.W. Spatafora (Eds.). The Mycota VII part A. Systematics and Evolution (2 ${ }^{\text {nd }}$ edition), Pp. 373-429. SpringerVerlag Berlin Heidelberg.

Hubregtse, J. (2019). Fungi in Australia, rev. 2.2. Field Naturalists Club of Victoria Inc. http://www.fncv.org.au/fungi-in-australia/

Kendrick, B. (2000). The Fifth Kingdom. ( $3^{\text {rd }}$ edition). Focus Publishing R. Pullins Company. Krug, J. C., Benny, G. L. \& Keller, H. W. (2004). Coprophilous fungi. In G.M. Mueller, G.F. Bills \& M.S. Foster (Eds.). Biodiversity of Fungi: Inventory and Monitoring Methods. Pp. 467-499. Elsevier Academy Press.

Kuo, M. (2019). Glossary. (MushroomExpert.Com). http://www.mushroomexpert.com/glossary.html. Diakses 12 Juli 2020. 
Kusrinah \& Kasiamdari, R. S. (2015). Morphological characteristics and kinship relationship of mushroom Schizophyllum commune Fr. Journal of Natural Sciences and Mathematics Research, 1(2), 65-71. https://doi.org/10.21580/jnsmr.2015.1.2.1620

Retnowati, A. (2018). The species of Marasmiellus (Agaricales: Omphalotaceae) from Java and Bali. Gardens' Bulletin Singapore, 70(1), 191-258. https://doi.org/10.26492/gbs70(1).2018-17

Tjitrosoepomo, G. (2011). Taksonomi Tumbuhan Schizophyta, Thallophyta, Bryophyta, Pteridophyta (cetakan kesembilan). Gadjah Mada University Press.

Tjitrosoepomo, G. (2017). Taksonomi Umum: Dasar-dasar Taksonomi Tumbuhan (cetakan keenam). Gadjah Mada University Press. 